\title{
Is social life cycle assessment really struggling in development or is it on a normal path towards harmonization/standardization?
}

\author{
Marzia Traverso ${ }^{1}$
}

Received: 19 July 2017 / Accepted: 2 August 2017 / Published online: 4 October 2017

(C) Springer-Verlag GmbH Germany 2017

Social life cycle assessment (S-LCA) has been already introduced in the scientific literature in 1996 with the term "societal LCA" (O'Brian M et al. 1996), but today it seems that it has not yet reached complete acceptance from the scientific community. Indeed, being among the three methodologies that assess the (environmental, economic, and social) impacts of a product's life cycle, it is the most discussed in the last decade, in particularly since the guidelines for social life cycle assessment were published by the UNEP/SETAC Life Cycle Initiative in 2009 (UNEP/SETAC 2009; Benoît et al. 2010). On one hand, it makes sense that this technique is less standardized compared to the other two and still presents many challenges in its implementation and in the definition of impact pathways; on the other hand, often the scientific discussion focuses too much attention on searching to legitimize models for the social and anthropologic aspects using an engineering approach to life cycle thinking (Iofrida et al. 2017).

We should not forget the main reasons that brought us to the development of social life cycle assessment in the first place:

1. The necessity to model and assess the three dimensions of sustainability in the evaluation of a product life cycle (UNEP/SETAC 2009) and, consequently, to evaluate the social impact complementary to the life cycle assessment (LCA) and life cycle costing (LCC) already used in the scientific and business world.

Responsible editor: Mary Ann Curran

Marzia Traverso

marzia.traverso@inab.rwth-aachen.de

1 Institute of Sustainability for Civil Engineering, RWTH Aachen, 52074 Aachen, Germany
2. Even more importantly, the need to assess consumption and production towards sustainable development by improving social, environmental, and economic performances of products along its life cycle. It leads to the necessity of a comprehensive and holistic evaluation method to avoid improvements in a phase or in an area of protections causing a decrease in another, or shifting problem without really improving the product sustainability performance. It can easily happen. For example, increasing the use of bio-plastics in several sectors, e.g., automotive industry, and/or biodiesel to reduce global warming potential (GWP) but increasing the risk to social impacts in the agricultural sector (often the raw materials are produced in emerging countries) resulting in the "food and fuel conflict" (Teller-Tank in German) (OECD-FAO 2017).

The most commonly accepted framework for a comprehensive sustainability assessment of product life cycle is defined by the following informal equation (Finkbeiner et al. 2010; Klöpffer 2008):

$L C S A=\mathrm{LCA}+\mathrm{LCC}+\mathrm{S}-\mathrm{LCA}$

It was developed to support the decision-making process in the development of a new product and in assessing the impacts along its life cycle. Particularly, those related to the development of a new product, experts and non-experts of sustainability, are often involved. That is one of the reason why it is preferable handle decisions with numerical indicators that have an intrinsic value than with qualitative measurement that can be easily misinterpreted. This leads again to an engineering approach for S-LCA.

The LCSA has been as well criticized because it does not really perform the integrative aspect of the sustainability 
concept ... but, in practice, evaluations mainly consist of merging or comparing final results from separate assessments (Iofrida et al. 2017). The same criticism could be directed towards LCA, because it assesses impacts by using indicators of different areas of protection and in the interpretation phase trade-offs and trend to define the best scenario. This approach for LCA is now completely accepted and is no longer criticized since it has been standardized according to the ISO norms. But is standardization a good legitimization tool for a methodology and, from a top-down perspective, maybe the only one? But what about a bottom-up perspective, in other words, from the life cycle approach users?

On the bottom-up perspective, several case studies and implementations of LCA to a product life cycle have been made in the last 50 years that have further led validation by the scientific community. What about S-LCA implementation? Even if S-LCA has not been scientifically accepted, interest in the business sector has risen noticeably in the last few decades. We can find several attempts to harmonize the methodology and the indicators at the practical level. A valid example includes the Roundtable of Product Social Metrics, a group of international companies representing the first bottom-up initiative to develop a practical, and feasible methodology to assess social impact of a product life cycle. Starting from the current scientific literature, they developed a qualitative and quantitative methodology called Product Social Impact Assessment (Fontes et al. 2016). Both methodologies have been implemented in case studies (Fontes et al. 2016; Traverso et al. 2016, Zanchi et al. 2016).

Another example is the Social Life Cycle Metrics for Chemical Products-A guideline by the chemical sector to assess and report on the social impact of chemical products, produced by a working group of World Business Council of Sustainable Development. This guidance presents social life cycle metrics and is the first of its kind for the chemical industry. It enables chemical companies to assess and report on social impacts of chemical products within the full value chain, by taking a life cycle approach (WBCSD 2016).
Other criticisms of social LCA relate to data and impact indicators. Some 50 years ago, the LCA community was similarly criticized, until consulting companies and universities decided to make a concerted effort to collect data from industries and supply chains. This is why further efforts should be directed to support users and researcher in finalizing the development of social impact pathways and a relevant social database.

\section{References}

Benoît C, Norris GA, Valdivia S, Ciroth A, Moberg A, Bos U, Prakash S, Ugaya C, Beck T (2010) The guidelines for social life cycle assessment of products: just in time! Int J Life Cycle Assess 15:156-163

Finkbeiner M, Schau EM, Lehmann A, Traverso M (2010) Towards life cycle sustainability assessment. Sustainability 2(10):3309-3322

Fontes et al (2016) Handbook of product social impact assessment version 3.0 (2016). Http://product-social-impact-assessment.com/ visited on 22.01.2016

Iofrida N, Strano A, Gulisano G, De Luca AI (2017) Why social life cycle assessment is struggling in development? Int J Life Cycle Assess. doi:10.1007/s11367-017-1381-0

Klöpffer W (2008) Life cycle sustainability assessment of products. Int J Life Cycle Assess 13(2):89-95

O’Brien, M., Doig, A., Clift, R. (1996). Social and Environmental Life Cycle Assessment (SECLA). International Journal of Life Cycle Assessment, 1(4):231-237

OECD-FAO (2017) Agricultural Outlook 2007-20167. April 2007

Traverso M, Bell L, Saling P, Fontes J (2016) Towards social life cycle assessment: a quantitative product social impact assessment. Int $\mathbf{J}$ Life Cycle Assess. doi:10.1007/s11367-016-1168-8

UNEP/SETAC (2009) Guidelines for social life cycle assessment of products. United Nations Environment Program, Paris SETAC Life Cycle Initiative United Nations Environment Programme

WBCSD (2016) Social life cycle metrics for chemical products - a guideline by the chemical sector to assess and report on the social impact of chemical products, based on a life cycle approach, WBCSD, November 2016. ISBN: 978-2-940521-52-4

Zanchi L, Delogi M, Zamagni A, Pierini M (2016) Analysis of the main elements affecting social LCA applications: challenges for the automotive sector. Int J Life Cycle Assess. doi:10.1007/s11367-0161176-8 